Applied Multivariate Research, Volume 13, No. 2, 2010, 145-159

\title{
THE FACETS OF JOB SATISFACTION: A NINE-NATION COMPARATIVE STUDY OF CONSTRUCT EQUIVALENCE
}

\author{
Catherine T. Kwantes ${ }^{1}$ \\ University of Windsor
}

\begin{abstract}
Archival data from an attitude survey of employees in a single multinational organization were used to examine the degree to which national culture affects the nature of job satisfaction. Responses from nine countries were compiled to create a benchmark against which nations could be individually compared. Factor analysis revealed four factors: Organizational Communication, Organizational Efficiency/Effectiveness, Organizational Support, and Personal Benefit. Comparisons of factor structures indicated that Organizational Communication exhibited the most construct equivalence, and Personal Benefit the least. The most satisfied employees were those from China, and the least satisfied from Brazil, consistent with previous findings that individuals in collectivistic nations report higher satisfaction. The research findings suggest that national cultural context exerts an effect on the nature of job satisfaction.
\end{abstract}

Keywords:

\section{INTRODUCTION}

With the rapid increase of globalization, national cultural context has become an important variable in understanding work behaviour. A current and critical challenge accompanying globalization in organizations is to understand how cultural values and expectations affect attitudes toward work (Ryan, Chan, \& Ployhart, 1999; Erez, 1994). While job satisfaction may be a universal phenomenon, cultural factors may impact what employees actually focus on when determining what their level of job satisfaction is. Gelfand, Raver, and Ehrhart (2002) point out that that "a construct that is found to be universal may be manifested differently in different cultures" (p.218). Given that job satisfaction is related to the degree to which one's needs related to work are satisfied (Shaffer, Joplin, Bell, Lau, \& Oguz, 2000) as well as the fact that many of these needs are culturally defined (Olie, 1996) cultural determinants of job satisfaction deserve attention.

\footnotetext{
${ }^{1}$ Correspondence and requests for reprints should be addressed to Catherine T. Kwantes, Department of Psychology, University of Windsor, Windsor, Ontario, Canada, N9B 3P4, or email at ckwantes@uwindsor.ca.

Author Note: An earlier version of this paper was presented at the Academy of International Business annual conference, Monterey, CA, US, 2003.
} 
While many researchers have examined the antecedents and consequences of job satisfaction, and others have compared overall levels of job satisfaction across groups (see, for example, Cass, Siu, Faragher, \& Cooper, 2003; Judge, Heller, \& Mount, 2002; Dormann $\&$ Zapf, 2001), little research has actually compared the components of job satisfaction across cultures. Theory suggests that a number of factors contribute to an individual's satisfaction with his/her job. However, the degree to which these factors actively make a difference in an individual's overall evaluation of the degree to which a job is satisfying, and what causes some factors to be salient in one context and others in another context, has received little attention. Rather, job satisfaction is frequently treated as either a dichotomous (one is satisfied or one is not satisfied with one's job), or ordinal (the degree to which one has overall job satisfaction) construct rather than examining the components of job satisfaction, and how those components are utilized by individuals in different contexts to determine satisfaction with his/her job (for example, Rode, 2004; Eskildsen, Kristensen, \& Westlund, 2004).

\section{Construct Equivalence Across Cultures}

To understand global differences in job satisfaction, however, it is important to go beyond focussing on differences in overall estimates of job satisfaction alone; the transcultural equivalency of the construct of job satisfaction must be investigated. Therefore, one of the first, and most fundamental, questions in transcultural comparative research is the extent to which any given construct developed and originally measured in one culture can exist and operate similarly in another cultural context (see van de Vijver and Leung, 1997, Gelfand, Raver, and Ehrhart, 2002). Without establishing construct equivalence, it is impossible to have confidence that any differences found in cross-cultural comparative work are actually due to organizational phenomena rather than differences due to a methodological artefact. Ryan, Chan, and Ployhart (1999) recently addressed the issue of construct equivalence using an employee attitude survey in a multinational organization to examine language and culture as potential factors involved in measurement equivalence across multinational samples. They used samples in Australia, Mexico, Spain, and the U.S. Surveys were given in English to the Australian and American respondents, and in Spanish to the Mexican and Spanish respondents. Measurement equivalence, defined in this case as equal factor loadings across groups, was not found in this study. The researchers noted that a confirmatory factor analysis indicated a good fit, however, suggesting that the lack of measurement equivalence does not preclude equivalence in practical terms.

In a study that explicitly examined measurement equivalence of a job satisfaction measure across national contexts, Liu, Borg, and Spector (2004) examined the effects of both language and culture on the German Job Satisfaction Survey. They clustered the 15 countries and areas their sample came from into four cultural groups based on Schwartz's (1999) cultural model. Their findings indicate that measurement equivalence is particularly high when an instrument is used with groups where the language and culture are similar to the language and cultural context within which the instrument was developed.

\section{Levels of Job Satisfaction Across Cultures}

Evidence from recent transcultural research suggests that an employee's national culture context can affect his or her level of overall job satisfaction. For example, Van de Vliert and Janssen (2002) found international differences in job satisfaction level, as measured by a fouritem measure derived from the International Value Research project among 42 different 
countries. They found the highest level of job satisfaction was in Switzerland, followed by Norway and Iceland (with the percentage of respondents reporting favourable ratings for job satisfaction $85 \%, 78 \%$ and $76 \%$, respectively) with the lowest levels in Hong Kong, Korea, and Taiwan (52\%, 53\%, and 55\% favourable ratings, respectively) On the other hand, SousaPoza and Sousa-Poza (2000) examined data from a cross-national study of job satisfaction that spanned 21 countries, specifically looking at differences in job satisfaction, and found that, while differences in ranking do exist in employee reports of job satisfaction, their data indicated that overall job satisfaction was high across all samples. In order to explain the differences in relative job satisfaction levels, Sousa-Poza and Sousa-Poza examined the ratio of work inputs (such as schooling, work time, and degree of danger) with work outputs (such as income, security, advancement opportunities, intrinsic interest). Differences in this ratio were found to correlate with differences in the reported level of job satisfaction in each country. Further, some determinants of job satisfaction (interesting work, for example) were to be found in each of the countries in their sample, suggesting that job satisfaction is likely to be high, regardless of national culture context, when employees view their jobs as interesting, and where relationships with management are good. Other determinants (pay and job security, for example) were found in some countries and not in others, suggesting that some determinants of job satisfaction may be more salient within certain specific national contexts.

\section{Determinants of Job Satisfaction}

Another avenue of research examining job satisfaction across cultures has examined whether predictors of job satisfaction operate differently across cultural contexts. Sekaran (1981), for example, examined the degree to which measures of job satisfaction developed in the United States are appropriate for the Indian context. Identical questionnaires were given to bank employees in the U.S. and in India. Using factor analysis results, it was concluded that the job satisfaction measure was equally applicable in India and the United States. Several differences related to national culture context emerged, however, in the salience of different factors related to job satisfaction. Regression analysis indicated that job variety and stress were common predictors to both cultures, but income was an important predictor only in the U.S. and communication of policies was an important predictor only in India. In a study that compared more than two national contexts, Shaffer, Joplin, Bell, Lau, and Oguz (2000) examined the experiences of female employees with respect to the effect of gender discrimination on job satisfaction in the United States, Hong Kong, and the People's Republic of China (PRC). After establishing measurement equivalence through principal components factor analysis and structural equation modelling, they determined that job satisfaction was significantly higher in female employees from the United States than in Hong Kong, and the People's Republic of China, despite the fact that women in the United States reported more gender harassment than did women in the other countries. Female employees in Hong Kong and the PRC reported lower levels of job satisfaction, yet higher levels of gender evaluation and unwanted sexual attention respectively.

Other research has examined specific cultural factors and how they may impact an employee's job satisfaction. Eylon and Au (1999), for example, hypothesized that differences in job satisfaction would emerge between high and low power distance when employees were empowered by management. In a management simulation exercise they found that the interaction between cultural context and empowerment did affect work performance, however, contrary to their expectations, job satisfaction did not significantly differ between the two samples. Extending this idea somewhat, Chiu and Kosinski (1999) suggested that 
personality traits are, to an extent, culturally determined, and that personality and culture may affect which factors are most salient to job satisfaction. Using samples from Singapore, Hong Kong, Australia, and the United States, they examined the interaction between personality traits and the cultural dimensions of individualism and collectivism, hypothesizing that individuals with high levels of individualism will also have high levels of positive affectivity and high levels of job satisfaction. Their results suggest that individualists with high positive affectivity and collectivists with high negative affectivity report the highest levels of job satisfaction.

\section{Content Areas of Job Satisfaction}

Job satisfaction is arguably one of the most researched concepts in organizational behaviour (Judge, Parker, Colbert, Heller, \& Ilies, 2002) and this research has produced a wealth of constructs that potentially relate to job satisfaction. Intriguing evidence suggests, however, that these content areas of job satisfaction do not function equivalently across all cultural or national samples and, in fact, may not be perceived equally. In 1973, for example, O'Reilly and Roberts examined job satisfaction response patterns in samples of white and non-white nurses. They concluded that culture serves as a frame of reference when individuals think of job satisfaction, and therefore influences an employee's perceptions of their job. Furthermore, they suggest that culture may be a determinant in which factors are considered most salient to job satisfaction. Simonetti and Weitz (1972) found that nationality affected the degree to which aspects of a job were taken into account when individuals were asked to determine the overall degree of job satisfaction they experienced. In research that used employees located in three national contexts from a single multinational corporation, they found that patterns of factor contribution to overall job satisfaction differed in respondents in each location. Differences were also found in general levels of extrinsic and intrinsic job satisfaction dimensions. More recently, Al-Mashaan (2003) explored differences in Type A personalities and different content areas of job satisfaction in a sample of teachers in Kuwait and Egypt. No differences were found in overall level of job satisfaction between the two national samples, however, differences were found in several content areas of job satisfaction. Specifically, the Egyptian sample reported higher levels of satisfaction in areas such as satisfaction with work itself, satisfaction with organizational design and structure, and satisfaction with personal relationships. Thus, a more detailed examination of these areas of job satisfaction highlighted differences that were not immediately apparent in a more global comparison of the job satisfaction construct.

\section{Present Research Goals}

The goal of the present research was to assess similarities and differences in the content area of job satisfaction across a multinational sample as well as to examine the degree to which each factor makes a differential contribution to overall job satisfaction in each national context. The use of an attitude survey from a multinational organization in this research is particularly salient given the fact that these organizations often use instruments of this sort to collect data from employees. These instruments are characteristically developed within one cultural or national context, and then disseminated to the rest of the organization with the implicit assumption that the items and questions asked will have equivalent meaning to each employee, regardless of his or her national or cultural context. It is expected that the content areas of job satisfaction will not have construct equivalence across all national samples 
(Hypothesis 1) as national context will result in different construct interpretations and meanings. In line with previous research, it is also expected that national samples will have differing levels of overall job satisfaction, despite the fact that each sample of employees came from the same multinational organization (Hypothesis 2). Finally, it is expected that national context will affect the degree to which specific content areas predict employees' overall level of job satisfaction (Hypothesis 3) as cultural, economic, social, and political factors will differ in each setting.

\section{METHOD}

To examine job satisfaction across nine nations, several analyses were employed. The first analysis focussed on the determinants of job satisfaction reported by employees of a single organization, and the cross-cultural construct equivalency of these determinants by examining the degree to which agreement existed between nations in the factor structure of the data, as well as interpretation and perspectives on each factor. This was followed by an examination of the degree of job satisfaction reported by respondents in each nation to see if any statistical differences existed in the overall level of job satisfaction between nations. Finally, within nation analyses looked for any differential contribution of factors to explaining the level of job satisfaction.

Data came from an archival data set of employee attitudes measured in 1999 at a single organization headquartered in the United States with manufacturing and sales facilities located globally. The data were gathered as a result of an internal survey focussing on employee attitudes toward the organization and their supervisors. Respondents for this project were selected if they worked outside the United States, and were chosen from the larger data set based on the number of respondents from each country. Eliminating responses from countries with fewer than 150 respondents resulted in a sample of 6299. Participants were from England $(n=1471)$, Canada $(n=336)$, China $(n=1245)$, Romania $(n=907)$, Poland $(n$ $=522)$, South Africa $(n=163)$, Brazil $(n=324)$, France $(n=838)$ and India $(n=493)$. Individuals responded to an internal organizational questionnaire asking them to report their perceptions of organizational activity ranging from the degree of communication received from supervisors to the degree of efficiency in organizational processes to the degree to which they benefited personally when the organization performed well. A Likert scale with responses ranging from 1 (strongly agree) to 5 (strongly disagree) was used.

\section{RESULTS}

Determination of Factor Structure. Questions regarding aspects of work that have been shown in previous theory or research (eg. Hackman \& Oldham, 1976) to relate to job satisfaction were selected from the larger set of questions in the survey. Responses to these questions were then subjected to exploratory factor analysis to determine the underlying factor structure. In order to avoid any one national response set from having a disproportionate effect on the pooled data, the data were weighted so each nation contributed approximately $11.1 \%$ of the total sample. The weighted, pooled dataset was then factor analyzed using principal components analysis followed by varimax rotation. After eliminating factors with eigenvalues less than one, and after examining the scree plot, four factors emerged, contributing $60 \%$ of the total variance in job satisfaction, and were labelled Communication, Organizational Efficiency/Effectiveness, Organizational Support, and 
Personal Benefit. Items were retained if their factor loading was greater than .40. Items with high loadings on two or more factors were eliminated from further analyses.

An item analysis was conducted, and items that reduced the total reliability of the factor solution were also eliminated from further analysis. One item was removed from the Organizational Efficiency/Effectiveness factor, and three from the Organizational Support factor. A final exploratory analysis was run, again using principal components analysis and varimax rotation, on the remaining items, resulting in the final scales. The Communication factor included seven items, such as "the performance expectations for my job have been clearly communicated to me." The Organizational Efficiency/Effectiveness factor also included seven items, such as "work flow processes are efficient and well organized where I work." The other two factors were comprised of two items after item analysis indicated that several items were not a good fit. The retained questions for Organizational Support included "I am provided with the support I need to do a quality job" while the Personal Benefit factor included "the better my performance the better my compensation will be." These factors are consistent with what has been found in previous research to relate to job satisfaction (for example: Bartlett, 2000; Pettit, Goris, \& Vaught, 1997; Williams, Malos, \& Palmer, 2002; Behson, 2002). Means, standard deviations, and reliabilities for each of the four factors, by nation, may be found in Table 1 and correlations between factors by country in Table 2 .

Table 1

\section{Means and Standard Deviations}

\begin{tabular}{|c|c|c|c|c|c|c|c|c|c|c|c|c|}
\hline \multirow[b]{2}{*}{ ( } & \multicolumn{3}{|c|}{$\begin{array}{c}\text { Organizational } \\
\text { Communication }\end{array}$} & \multicolumn{3}{|c|}{$\begin{array}{l}\text { Organizational } \\
\text { Efficiency } \\
\text { /Effectiveness }\end{array}$} & \multicolumn{3}{|c|}{$\begin{array}{l}\text { Organizational } \\
\text { Support }\end{array}$} & \multicolumn{3}{|c|}{ Personal Benefits } \\
\hline & $\mathrm{M}$ & SD & $\alpha$ & M & SD & $\alpha$ & $\mathrm{M}$ & SD & $\alpha$ & $\mathrm{M}$ & SD & $\alpha$ \\
\hline Brazil & 2.48 & .79 & .90 & 2.86 & .73 & .74 & 2.36 & 1.06 & .80 & 2.44 & 1.00 & .51 \\
\hline Canada & 2.52 & .88 & .90 & 3.01 & .78 & .84 & 2.28 & 1.16 & .87 & 2.84 & 1.05 & .77 \\
\hline China & 2.15 & .74 & .86 & 2.28 & .67 & .85 & 2.39 & 1.08 & .88 & 2.56 & 1.20 & .76 \\
\hline England & 2.82 & .83 & .89 & 2.95 & .68 & .81 & 2.52 & 1.04 & .85 & 3.20 & 1.07 & .76 \\
\hline France & 2.41 & .72 & .87 & 2.58 & .62 & .79 & 2.32 & 0.89 & .81 & 3.23 & 0.97 & .70 \\
\hline India & 2.61 & .85 & .83 & 2.70 & .76 & .79 & 2.88 & 1.20 & .85 & 2.54 & 1.04 & .56 \\
\hline Poland & 2.22 & .72 & .90 & 2.38 & .60 & .81 & 2.44 & 0.94 & .84 & 3.59 & 1.03 & .87 \\
\hline Romania & 2.19 & .77 & .85 & 2.35 & .67 & .75 & 2.51 & 1.18 & .85 & 2.86 & 1.20 & .79 \\
\hline $\begin{array}{l}\text { South } \\
\text { Africa }\end{array}$ & 2.56 & .84 & .84 & 2.72 & .67 & .78 & 2.68 & 1.11 & .70 & 2.94 & 1.07 & .61 \\
\hline
\end{tabular}

Exploration of Construct Equivalence. Before any meaningful comparison between responses across cultural divides can be made, it is necessarily to be sure that individuals in all cultures have similar understandings of the items asked, as well as the construct that the items are intended to measure (Liu, Borg, \& Spector, 2004). Therefore, the second phase of this study examined the degree to which these four factors could be assumed to have the same meaning in each national cultural context. Following procedure recommended by van de Vijver and Leung (1997) for assessing construct equivalence, the factors from each nation were rotated using a Procrustes rotation, with the factor structure of the weighted, pooled sample serving as the target matrix. A coefficient of agreement between the factor loading on the weighted, pooled factor solution and the factor solution for each country was then 
computed. This coefficient indicates the degree to which a factor has similar endorsement in two different samples.

Table 2

Correlations between Factors

\begin{tabular}{|c|c|c|c|c|}
\hline \multirow[t]{3}{*}{ England } & Communication & $\begin{array}{l}\text { Efficiency } \\
.597^{* * *}\end{array}$ & $\begin{array}{l}\text { Support } \\
.481^{* * *}\end{array}$ & $\begin{array}{l}\text { Benefit } \\
.484^{* *}\end{array}$ \\
\hline & Efficiency & 1.00 & $.584^{* *}$ & $.521^{* *}$ \\
\hline & Support & & 1.00 & $.380^{* *}$ \\
\hline \multirow[t]{3}{*}{ Canada } & Communication & $.702^{* *}$ & $.514^{* *}$ & $.683^{* *}$ \\
\hline & Efficiency & 1.00 & $.573^{* *}$ & $.625^{* *}$ \\
\hline & Support & & 1.00 & $.370^{* *}$ \\
\hline \multirow[t]{3}{*}{ China } & Communication & $.544^{* * 1}$ & $.329^{* * * *}$ & $.481^{\text {*** }}$ \\
\hline & Efficiency & 1.00 & $.533^{* *}$ & $.523^{* *}$ \\
\hline & Support & & 1.00 & $.314^{* *}$ \\
\hline \multirow[t]{3}{*}{ Brazil } & Communication & $.570^{* *}$ & $.424^{* *}$ & $.388^{* *}$ \\
\hline & Efficiency & 1.00 & $.523^{* *}$ & $.315^{* *}$ \\
\hline & Support & & 1.00 & $.235^{* *}$ \\
\hline \multirow[t]{3}{*}{ France } & Communication & $.581^{* *}$ & $.475^{\text {** }}$ & $.487^{* *}$ \\
\hline & Efficiency & 1.00 & $.548^{* *}$ & $.461^{* *}$ \\
\hline & Support & & 1.00 & $.395^{* *}$ \\
\hline \multirow[t]{3}{*}{ Romania } & Communication & $.611^{* * *}$ & $.508^{* * *}$ & $.470^{* * *}$ \\
\hline & Efficiency & 1.00 & $.554^{* *}$ & $.552^{* *}$ \\
\hline & Support & & 1.00 & $.402^{* *}$ \\
\hline \multirow[t]{3}{*}{ Poland } & Communication & $.603^{* *}$ & $.528^{* *}$ & $.485^{* *}$ \\
\hline & Efficiency & 1.00 & $.573^{* *}$ & $.478^{* *}$ \\
\hline & Support & & 1.00 & $.413^{* *}$ \\
\hline \multirow[t]{3}{*}{ Romania } & Communication & $.534^{* * *}$ & $.479^{* * *}$ & $.499^{* * *}$ \\
\hline & Efficiency & 1.00 & $.482^{* *}$ & $.500^{* *}$ \\
\hline & Support & & 1.00 & $.438^{* *}$ \\
\hline \multirow[t]{3}{*}{ South Africa } & Communication & $.386^{\text {** }}$ & $.479^{* *}$ & $.304^{* *}$ \\
\hline & Efficiency & 1.00 & $.420^{* * *}$ & $.436^{* * *}$ \\
\hline & Support & & 1.00 & $.403^{* *}$ \\
\hline
\end{tabular}

$* p<.05, * * p<.01$ 
Table 3

Coefficients of Agreement between National Sub-Sample and Pooled, Weighted Total Sample

\begin{tabular}{lrrrr} 
& Communication & Efficiency & Support & Personal Benefit \\
\hline Brazil & 0.995 & 0.868 & 0.970 & 0.967 \\
Canada & 0.980 & 0.738 & 0.897 & 0.682 \\
China & 0.984 & 0.873 & 0.843 & 0.961 \\
England & 0.889 & 0.234 & 0.844 & 0.383 \\
France & 0.975 & 0.946 & 0.925 & 0.467 \\
India & 0.970 & 0.778 & 0.992 & 0.538 \\
Poland & 0.996 & 0.979 & 0.980 & 0.997 \\
Romania & 0.986 & 0.942 & 0.985 & 0.990 \\
South Africa & 0.986 & 0.927 & 0.890 & 0.868 \\
\hline
\end{tabular}

In this case, each national sample was compared with the pooled, weighted data to assess the degree to which each nation is similar to or different from the total group on factor scores. The weighted, pooled data thus formed a norm against which individual national samples may be compared for similarity. A coefficient of agreement over .90 indicates a high degree of similarity on a particular factor between a specific national sample and the norm, while a coefficient over .95 indicates that there is virtually no difference between the factors in the two samples (van de Vijver \& Leung).

Hypothesis 1 was supported, as no factors exhibited uniformly high construct equivalence, although some factors had more equivalence than others. Few differences were found on the Organizational Communication factor (see Table 3). Only England had a coefficient of agreement that indicated a less than identical construct equivalence with the norming sample $(e=.88)$. On the Organizational Efficiency/Effectiveness factor, however, greater differences emerged. Only Poland $(e=.98)$ had complete construct equivalence with the norming sample, although France, $(e=.95)$, Romania $(e=.94)$, and South Africa $(e=.93)$ each had a high degree of similarity with the weighted, pooled data. Coefficients of agreement from all the other nations were considerably different, ranging from $e=.87$ (China) and $e=.78$ (India) to a low of $e=.23$ (England). Views of Organizational Support varied less widely, with coefficients of agreement ranging from $e=.84$ (China and England) to $e=.99$ (Romania and India). The fourth factor, personal benefit, resulted in the most variability. Brazil, China, Poland, and Romania all had coefficients of agreement greater than .90. On the other hand, vast differences from the norm were found for Canada $(e=.68)$, England $(e=.38)$, France $(e$ $=.47)$, India $(e=.54)$ and South Africa $(e=.87)$. These wide ranging differences suggest that the items on this factor are being interpreted very differently in different nations, and that the perspectives on these items similarly vary considerably by nation.

Comparison of Overall Job Satisfaction Level. A single question was asked regarding the degree to which individuals were satisfied with their job. While single item indices are generally not considered sufficient to measure a construct, job satisfaction may be an exception to this heuristic. Wanous, Reichers, \& Hudy (1997), for example, suggest that the use of a single item to measure job satisfaction is not a "fatal flaw" in the research process. There is support for the idea that single-item measures are sufficient when the construct is a narrow one or is unambiguous to the respondent (Sackett \& Larson, 1990) and some research suggests that in the case of measuring job satisfaction, a single-item measure may actually be 
preferable to a scale of components of job satisfaction (Nagy, 2002; Scarpello \& Campbell, 1983). Accordingly, a one-way ANOVA was performed with nation as the independent variable and with responses to the single item job satisfaction question serving as the dependent variable, followed by multiple comparisons using a Bonferroni adjustment as well as a Student-Newman-Kuhls post hoc analysis. Hypothesis 2 was supported, as the results indicated significant differences, with China responding with the highest degree of job satisfaction $(M=3.66)$, followed by England $(M=2.85)$, then India $(M=2.71)$. Five countries comprised the next group of respondents, with no statistically significant difference between them: S. Africa $(M=2.55)$, France $(M=2.51)$, Canada $(M=2.50)$, Romania $(M=$ 2.50) and Poland $(M=2.41)$. Respondents from Brazil reported significantly lower job satisfaction then those from other nations $(M=2.10)$. This finding is somewhat consistent with earlier research indicating that, in general, individuals from more collectivistic countries are more likely to be satisfied with their jobs than individuals from individualistic countries (Hui, Yee, \& Eastman, 1995) as Brazil is considered to be moderately individualistic while China is considered a more collectivistic nation (Hofstede, 2001).

Comparison of Job Satisfaction Content Areas. To compare constructs across different contexts in cross-cultural research it is not unusual to construct one hierarchical regression equation that includes nation in the first step, then examines the degree to which independent variables have the ability to predict the dependent variable and look for interaction effects with nation and predictor variables. However, in this case, it was felt that this would be inappropriate given the fact that construct equivalence was not found for all variables in all samples. Accordingly, only within country analyses were performed to find the degree to which each of these factors significantly predicted job satisfaction within each individual group. Job satisfaction was regressed on Communication, Organizational Efficiency/Effectiveness, Organizational Support, and Personal Benefit. The regression equation significantly predicted job satisfaction in all nine countries, with the amount of variance explained ranging from a high of 55\% in Canada to a low of $17 \%$ in China (See Table 4).

Table 4

Summary of Regression Analysis for Factors Predicting Overall Job Satisfaction

\begin{tabular}{lllll|lll|ll|ll} 
& & \multicolumn{3}{c}{ Communication } & \multicolumn{3}{c}{ Efficiency } & \multicolumn{3}{c}{ Support } & \multicolumn{2}{c}{ Personal Benefit } \\
& $\mathrm{R}^{2}$ & \multicolumn{1}{c}{ Adj $\mathrm{R}^{2}$} & $\mathrm{~B}$ & $\mathrm{SE}$ & $\mathrm{B}$ & $\mathrm{SE}$ & $\mathrm{B}$ & $\mathrm{S} E$ & $\mathrm{~B}$ & $\mathrm{SE}$ \\
\hline Brazil & $0.32^{* *}$ & $0.31^{* *}$ & 0.13 & .07 & $0.16^{*}$ & .08 & $0.30^{* *}$ & .05 & $0.13^{* *}$ & .05 \\
Canada & $0.55^{* *}$ & $0.54^{* *}$ & $0.22^{* *}$ & .07 & $0.45^{* *}$ & .08 & $0.24^{* *}$ & .05 & $0.01^{*}$ & .05 \\
China & $0.17^{* *}$ & $0.17^{* *}$ & $0.16^{* *}$ & .05 & 0.11 & .06 & $0.19^{* *}$ & .03 & $0.14^{* *}$ & .03 \\
England & $0.38^{* *}$ & $0.38^{* *}$ & $0.30^{* *}$ & .03 & $0.25^{* *}$ & .04 & $0.16^{* *}$ & .03 & $0.17^{* *}$ & .03 \\
France & $0.44^{* *}$ & $0.44^{* *}$ & $0.19^{* *}$ & .04 & $0.22^{* *}$ & .05 & $0.25^{* *}$ & .03 & $0.17^{* *}$ & .03 \\
India & $0.50^{* *}$ & $0.50^{* *}$ & $0.11^{*}$ & .06 & $0.36^{* *}$ & .07 & $0.38^{* *}$ & .04 & $0.10^{*}$ & .04 \\
Poland & $0.39^{* *}$ & $0.38^{* *}$ & 0.12 & .05 & $0.35^{* *}$ & .07 & $0.11^{* *}$ & .04 & $0.20^{* *}$ & .03 \\
Romania & $0.44^{* *}$ & $0.44^{* *}$ & $0.17^{* *}$ & .04 & $0.14^{* *}$ & .05 & $0.22^{* *}$ & .03 & $0.23^{* *}$ & .03 \\
South & & & & & & & & & & \\
Africa & $0.28^{* *}$ & $0.26^{* *}$ & $0.42^{* *}$ & .09 & $-0.01^{*}$ & .12 & 0.12 & .08 & $0.20^{*}$ & .07 \\
\hline
\end{tabular}

While the equation predicting job satisfaction was significant in all countries, the degree to which each of the four factors contributed to the explanation of job satisfaction in different countries differed, supporting Hypothesis 3. All four factors were significant predictors in England, Canada, France, and Poland. Communication did not provide an independent 
contribution to the job satisfaction regression equation in India and Brazil, while Efficiency did not in China. The regression equation for South Africa included only communication and personal benefit as significant predictors of job satisfaction.

\section{DISCUSSION}

The results from these analyses suggest that, while differences exist in the level of job satisfaction in different countries, even greater discrepancies exist in defining what aspects of a job contribute to a perception of satisfaction or dissatisfaction. Attention in transcultural research has shifted from investigating what factors are important in defining satisfaction with the job to examining how antecedents differentially predict overall job satisfaction in different contexts (for example, Vigoda, 2001). The findings of this research suggest that it would be prudent to return to an examination of what aspects of a job are valued in different cultures and how those value differences are reflected in how aspects of a job are perceived.

Organizational Communication and Organizational Support were the components of job satisfaction where most agreement existed across national samples, while Organizational Efficiency/Effectiveness and Personal Benefit resulted in much more disparate perspectives. Of these four factors, the convergence of understanding with respect to the Organizational Communication construct and the divergence of understanding with respect to the construct of Personal Benefit are the most easily understood. The finding that so much agreement existed with regard to communication may be due to the fact that most of the items relating to this factor refer to behaviours and practices that are common in organizations globally, and therefore would likely have similar meaning to individuals across national borders. Further, the fact that all respondents were from one organization may have reduced the degree to which disparate understandings or perspectives exist on this factor.

On the other hand, the items regarding personal benefit were ones that allowed more room for unique interpretations. The term "benefit" may be thought of in several ways, for example, as a monetary benefit or as a status benefit. In this survey, no attempt was made to clarify specific interpretations of this term, therefore it is possible that any agreement or disagreement that exists between samples is the result of wording effects rather than actual agreement or disagreement about a unitary construct.

National culture orientation, however, may explain some of the differences found in the other dimensions. Cultural expectations may vary considerably with regard to what does and what does not constitute organizational support. Hofstede (1997) points out that organizations are focussed on individuals in some societies and on groups in others. Expected support in an individualist context is likely to include support aimed at individual effort, while in a collectivistic context, support is more likely to be defined as interventions aimed at a group effort. Yoon and Lim (1999) found support for the idea that perceptions of what constitutes organizational support differ as the result of individualism and collectivism. In a collectivistic context, relationships are perceived as an integral part of organizational support, while in more individualistic contexts, perceptions of support have more of an economic exchange component. Similarly, in a high power distance context, organizational support is more likely to be perceived as clear and explicit direction while in a low power distance context, support is more likely to be seen as providing a climate where those closest to the work are supported to make their own decisions relating to the work process. These cultural differences in perspective likely spill over into the differences in perspective regarding organizational efficiency/effectiveness as well, since the two concepts are highly interrelated (Yoon \& Lim, 1999). Indeed, empirical evidence supports the idea that national 
culture value orientations do affect work attitudes in general, and job satisfaction in particular (Sparrow \& Wu, 1998; Bae \& Chung, 1997; Saiyadain, 1985).

While the results of this study do not explicitly tease out culture from other national differences that may affect attitudes toward job satisfaction, some intriguing findings emerged. Respondents from both Brazil and India indicated that organizational communication was not a salient factor in determining job satisfaction. Both of these nations have been found to have hierarchical social cultures - Hofstede (2002) found both Brazil and India to rank $10^{\text {th }}$ and $14^{\text {th }}$ respectively out of 50 countries on power distance, with Power Distance Index Values almost twice that of Great Britain or Canada. Endorsement of power distance implies that consultative managers are viewed with less respect than authoritative managers in organizations, and that task oriented leadership is preferred to relationship oriented leadership (Hofstede, 2002). Not expecting organizational communication in high power distance contexts corresponds to these characteristics, and aids in explaining why this factor did not contribute to explaining the degree of job satisfaction in these national contexts.

Respondents from China indicated that only organizational efficiency/effectiveness was unrelated to job satisfaction. Again, national culture values may be seen at work here. Organizational cultures in the Chinese context have been shown to distinctly reflect Chinese social culture (Kwantes, Boglarsky, \& Kuo, 2004). Imbedded in Chinese culture is a strong desire for social acceptance (Bond, 1996; Hosfstede, 2001), and therefore a common focus is on the preservation of social harmony - a focus which may, at times, be at odds with the concepts of efficiency and effectiveness. Furthermore, China consistently ranks as a culture with a very strong emphasis on long-term orientation with its attendant characteristics of persistence, perseverance, and a perspective that precludes an expectation of quick results (Hofstede, 2002). Discipline, moderation, tolerance, harmony, and non-competitiveness are values that have been shown to be consistent with a long-term orientation. Examining the individual items on the Efficiancy/Effectiveness factor, it is possible that the way this factor was operationalized in this study may have led to weak endorsement of these items in the Chinese cultural context, as the items emphasized encouragement to take calculated risks, permission to make one's own decisions to improve organizational effectiveness, and efficient processes.

In the sample from South Africa, only organizational communication and personal benefits were considered salient to job satisfaction. South Africa has ranked relatively high on individualism in previous studies (Hofstede, 2002). This individualism, combined with the uncertainty, economic and political turmoil prevalent in South Africa today may aid in explaining these results. Organizational communication provides some clarity for employees regarding both individual and organizational progress, and this in turn provides some information regarding the viability of the organization. In an uncertain time, this information, along with the degree to which one personally benefits from one's job become more tangible than support or efficiency of the organization as a whole. In a national context of individualism, it is not surprising that factors relating most directly to an individual's personal outcomes would be most salient.

\section{CONCLUSION}

Satisfaction is one of the most widely used attitudinal measures in organizations, and is also one of the most widely used attitudinal variables in research. It is frequently used as a summary measure of other employee attitudes such as acceptance and contentment (Hodson, 2002). From the perspective of both research and practice, a better understanding of how 
national culture contexts affect both the definition and content areas of job satisfaction is warranted. This research contributes to the literature by providing initial evidence that the operationalization of job satisfaction may be affected by national context, and that any comparison of job satisfaction across national or cultural boundaries must take measurement equivalence but also construct equivalence into account. This is particularly salient in multinational corporations where comparisons across national contexts are used for organizational development decision making.

It must be noted, however, that this research focussed on national context and not explicitly on cultural context - while national context differences explained $18.5 \%$ of the variance in job satisfaction in this research project, culture alone does not likely explain all national differences. Differences in job attitudes may be the result of national political economy variables, national labor markets (Sparrow \& Wu, 1997) and other contextual factors unrelated to cultural values. Organizational factors such as HR policies and practices may also be involved in attitudinal differences. While examining job satisfaction within the confines of a single organization reduces the variability due to organizational factors, it does not eliminate it.

Nevertheless, the findings still strongly suggest a renewed investigation into the construct and content area equivalency of job satisfaction in different national culture contexts. The data used were archival and from an internal organizational attitude survey, therefore not chosen a priori to explicitly address this research question. Future research using both qualitative and quantitative methods would be better suited to explicate possible differences in job satisfaction across national cultures. Isolating the research project to focus on a few number of countries would allow for a finer grained approach to hypothesizing the direction of differences, but more importantly, the potential causes for these differences. Future research including more variables, for example, explicit cultural value orientations of the respondents and demographic variables would help to elucidate the extent to which cultural factors provide independent explanations for attitudinal differences or act in conjunction with other variables and provide a much more detailed understanding of the meaning of the construct in different contexts.

\section{REFERENCES}

Al-Mashaan, O. S. (2003). Comparison between Kuwaiti and Egyptian teachers in Type A behavior and job satisfaction: A cross-cultural study. Social Behavior and Personality, 31,(5), 523-524.

Auster, E. R. (2001). Professional women's midcareer satisfaction: Toward an explanatory framework. Sex Roles, 44, 11-12, 719-750.

Bae, K., \& Chung, C. (1997). Cultural values and work attitudes of Korean industrial workers in comparison with those of the United States and Japan. Work and Occupations, 24, 1, 80-96.

Bartlett, C. (2000). Supervisory communication and subordinate job satisfaction: The relationship between superiors' self-disclosure, offers of help, offers of cooperation, frequency of contact, trust and subordinates' job satisfaction. Public Library Quarterly, $18,1,9-30$.

Behson, S. J. (2002). Which dominates? The relative importance of work-family organizational support and general organizational context on employee outcomes. Journal of Vocational Behavior, 61, 1, 53-72. 
Bond, M. H. (1996). Chinese values. In M. H. Bond (Ed.). The Handbook of Chinese Psychology (pp. 208-226). NY: Oxford University Press.

Cass, M. H., Siu, O. L., Faragher, E. B., \& Cooper, C. L. (2003). A meta-analysis of the relationship between job satisfaction and mployee health in Hong Kong. Stress \& Health, 19, 2, 79-95.

Chinese Culture Connection. (1987). Chinese values and the search for culture-free dimensions of culture. Journal of Cross-Cultural Psychology, 18, 143-164.

Chiu, R. K., Kosinski, F. A. (1999). The role of affective dispositions in job satisfaction and work strain: Comparing collectivist and individualist societies. International Journal of Psychology, 34, 1, 19-28.

Dormann, C., \& Zapf, D. (2001). Job satisfaction: A meta-analysis of stabilities. Journal of Organizational Behavior, 22,5, 483-504.

Erez, M. (1994). Toward a model of cross-cultural industrial and organizational psychology. In H. C. Triandis, M. D. Dunnete, \& L. M. Hough (Eds). Handbook of industrial and organizational psychology, Vol. 4. pp. 559-608. Palo Alto, CA, US: Consulting Psychologists Press.

Eskildsen, J. K., Kristensen, K., \& Westlund, A. H. (2004). Work motivation and job satisfaction in the Nordic countries. Employee Relations, 26, 2, 122-136.

Eylon, D., \& Au, K. Y. (1999). Exploring empowerment cross-cultural differences along the power distance dimension. International Journal of Intercultural Relations, 23, 3, 373385.

Gelfand, M. J., River, J. L., \& Ehrhart, K. H. (2002). Methodological issues in cross-cultural organizational research. In S. Rogelberg (Ed.) Handbook of Research Methods in Industrial and Organizational Psychology. Malden, MA, US: Blackwell.

Hackman, J. R., \& Oldham, G. R. (1976). Motivation through the design of work: Test of a theory. Organizational Behavior \& Human Decision Processes, 16, 2, 250-279.

Hodson, R. (2002). Demography or respect? Work group demography or organizational dynamics as determinants of meaning and satisfaction at work. British Journal of Sociology, 53, 2, 291-317.

Hofstede, G. (2001). Culture's consequences: Comparing values, behaviors, institutions, and organizations across nations $\left(2^{\text {nd }}\right.$ ed.). Thousand Oaks, CA: Sage.

Hofstede. G. (1997). Cultures and Organizations: Software of the Mind. New York: McGraw-Hill.

Hofstede, G. (1980). Culture's consequences: International differences in work-related values. Beverly Hills, CA: Sage.

Hui, C. H., Yee, C., \& Eastman, K. L. (1995). The relationship between individualismcollectivism and job satisfaction. Applied Psychology: An International Review, 44, 3, 276-282.

Judge, T. A., Heller, D., \& Mount, M. K. (2002). Five factor model of personality and job satisfaction: A meta-analysis. Journal of Applied Psychology, 87, 3, 530-541.

Judge, T. A., Parker, S. K., Colbert, A. E., Heller, D., \& Ilies, R. (2002). Job satisfaction: A cross-cultural review. In N. Anderson \& D. Ones (Eds.) Handbook of Industrial, Work and Organizational Psychology, Vol 2. Organizational Psychology. 25-52,Thousand Oaks, CA, US: Sage Publications.

Kwantes, C. T., Boglarsky, C. A., \& Kuo, B. C. H. (2004). One organization, three nations: Harmonies in organizational culture. Paper presented at the Third Biennial Conference on Intercultural Research, Taipei, Taiwan. 
Liu, C., Borg, I., \& Spector, P. E. (2004). Measurement equivalence of the German Job Satisfaction Survey used in a multinational organization: Implications of Schwartz's culture model. Journal of Applied Psychology, 88(6), 1070-1082.

Olie, R. (1996). The 'culture' factor in personnel and organizational policies. In A. W. Harzing \& J. Van Ruysseveldt (Eds.) International Human Resource Management (pp. 124-133). London: Sage.

O'Reilly, C. A., \& Roberts, K. H. (1973). Job satisfaction among whites and nonwhites: A cross-cultural approach. Journal of Applied Psychology, 57, 3, 295-299.

Pettit, J. D., Jr., Goris, J. R., \& Vaught, B. C. (1997). An examination of organizational communication as a moderator of the relationship between job performance and job satisfaction. Journal of Business Communication, 34, 1, 82-98.

Redding, G. \& Wong, G. Y. Y. (1986). The psychology of Chinese organizational behavior. In M. H. Bond (Ed.), The psychology of the Chinese people (pp. 267-295). NY: Oxford University Press.

Rode, J. C. (2004). Job satisfaction and life satisfaction revisited: A longitudinal test of an integrated model. Human Relations, 57, 9, 1205-1230.

Ryan, A. M., Chan, D., \& Ployhart, R. E. (1999). Employee attitude surveys in a multinational organization: considering language and culture in assessing measurement equivalence. Personnel Psychology, 52, 1, 37-58.

Sackett, P. R., \& Larson, J. R., Jr. (1990). Research strategies and tactics in industrial and organizational psychology. In M. D. Dunnette \& L. M. Hough, Eds. Handbook of Industrial and Organizational Psychology, Vol. 1, $2^{\text {nd }}$ Ed. P. 419-489. Palo Alto, CA, US: Consulting Psychologists Press, Inc.

Saiyadain, M. S. (1985). Personal characteristics and job satisfaction: India-Nigeria comparison. International Journal of Psychology Special Issue: Job satisfaction, 20, 2, 143-153.

Scarpello, V., \& Campbell, J. P. (1983). Job satisfaction: Are all the parts there? Personnel Psychology, 36, 3, 577-600.

Sekaran, U. (1981). Are U.S. organizational concepts and measures transferable to another culture? An empirical investigation. The Academy of Management Journal, 24, 2, 409417.

Shaffer, M. A., Joplin, J.R.W., Bell, M. P., Lau, T., \& Oguz, C. (2000). Gender discrimination and job-related outcomes: A cross-cultural comparison of working women in the United States and China. Journal of Vocational Behavior, 57, 3, 395-427.

Simonetti, S. H., \& Weitz, J. (1972). Job satisfaction: Some cross-cultural effects. Personnel Psychology, 25, 1, 107-118.

Sousa-Poza, A., \& Sousa-Poza, A. A. (2000). Well-being at work: A cross-national analysis of the levels and determinants of job satisfaction. Journal of Socio-Economics, 29, 517538.

Sparrow, P., \& Wu, P-C. (1998). Does national culture really matter? Predicting HRM preferences of Taiwanese employees. Employee Relations, 20, 1, 26-56.

Van de Vijver, F. J. R., \& Leung, K. (1997). Methods and Data Analysis of Comparative Research. In J. W. berry, Y. H. Poortinga, \& J. Pandey (Eds). Handbook of Cross-Cultural Psychology: Volume 1 Theory and Method. Boston: Allyn and Bacon.

Van de Vliert, E., \& Janssen, O. (2002). Better than: performance motives as roots of satisfaction across more and less developed countries. Journal of Cross-Cultural Psychology, 33, 4, 380-397. 
Vigoda, E. (2001). Reactions to organizational politics: A cross-cultural examination in Israel and Britain. Human Relations, 54, 11, 1483-1518.

Wanous, J. P., Reichers, A. E., \& Hudy, M. J. (1997). Overall job satisfaction: How good are single-item measures? Journal of Applied Psychology, 82, 2, 247-252.

Williams, M. L., Malos, S. B., \& Palmer, D. K. (2002). Benefit system and benefit level satisfaction: An expanded model of antecedents and consequences. Journal of Management, 28, 2, 195-215.

Yoon, J., \& Lim, J-C. (1999). Organizational support in the workplace: The case of Korean hospital employees. Human Relations, 52, 7, 923-945. 